\title{
Free functional gracilis muscle transfer for reconstruction of massive ectopic calcification following a lower extremity fracture: a case report and overview of the literature
}

\author{
Jürgen W. Schmitt • Beata Bode • Charles E. Dumont
}

Received: 21 February 2006 / Published online: 21 September 2006

(C) Springer-Verlag 2006

\begin{abstract}
We present a patient with massive posttraumatic ectopic calcification in the lower extremity. The patient complained of an increasing tender soft tissue mass with signs of acute inflammation and foot dorsiflexion weakness following a tibial fracture for 34 years. A large radiopaque mass was resected and reconstructed using a free functional gracilis muscle transfer, resulting in recovery of stable soft tissue and foot dorsiflexion. The resected material showed highly fibrosed soft tissue with extensive dystrophic calcifications. There were no sign of recurrence at 18 -month follow-up.
\end{abstract}

Keywords Soft-tissue calcification - Tibial fracture . Compartment syndrome $\cdot$ Peroneal nerve injury $\cdot$ Free functional gracilis muscle transfer $\cdot$ Surgical treatment

\section{Introduction}

The ectopic ossification is a well known complication following soft tissue injury, but it is rare. It has been reported as a late complication of a compartment syndrome [1-5]. There is only one report on ectopic

J. W. Schmitt $(\bowtie) \cdot$ C. E. Dumont

Department of Orthopedic Surgery, Balgrist Clinic,

University of Zurich, Forchstrasse 340,

Zurich 8008, Switzerland

e-mail: Juergen.Schmitt@balgrist.ch

C. E. Dumont

e-mail: Charles.Dumont@balgrist.ch

B. Bode

Department of Pathology, Institute of Clinical Pathology,

University Hospital, Zurich 8091, Switzerland calcification after tibial fracture combined with a nerve injury [6]. Although guidelines have been established for assessment [7, 8] and treatment [9] of compartment syndrome in the leg, little data has been collected on ectopic calcifications as a late sequelae of compartment syndrome.

Ectopic calcifications are commonly observed in soft tissues as a result of neoplastic or inflammatory disease, injury, and aging in the absence of a systemic mineral imbalance. In damaged tissue, the body responds in a nonspecific manner by a generic inflammatory response reaction. This sometimes results in calcium deposition within damaged or devitalized tissues.

We present a case of a massive and gradually increasing ectopic calcification of muscles in the lower extremity. The calcifications developed in connection with previous injury to the lower extremity related to a compartment syndrome and nerve injury. We report successful treatment by means of block resection of the lesion and reconstruction with a free functional gracilis muscle transfer.

\section{Case report}

A 53-year-old woman presented to our outpatient clinic with acute pain and swelling in the lower extremity. The onset of these symptoms followed 34 years of an asymptomatic period after injury. The patient sustained a closed tibiafibula fracture and was treated by intramedullary tibial nailing when she was 19 -year old. Simultaneously the patient suffered from a complex injury of the lumbosacral plexus with complete peroneal nerve palsy. Two years later the intramedullary 
nail was removed because of a nonunion. ORIF with cancellous bone grafting was performed. Removal of the implants was performed 5 years later. Between the last surgery and the current episode the patient complained of progressive limitation of the tibiotalar range of motion despite maintaining on active life style.

Clinical examination revealed a painful, tender soft tissue mass with erythema in the ventral third of the leg (Fig. 1). The patient observed that the mass had grown over the last 12 months. A puncture was done and exposed a tooth paste-like white material. The ankle active range of motion was $0^{\circ}$ of dorsiflexion to $20^{\circ}$ of plantarflexion. Active foot extension was graded as M3 and palpation revealed voluntary muscle contraction of the proximal fourth of the tibialis anterior muscle. Sensory loss was confined to the anteromedial lower leg and dorsal aspect of the foot corresponding to both superficial and deep peroneal nerve territories.

The white blood cell (WBC) count was 10,200 cells/ $\mathrm{mm}^{3}$ and C-reactive protein (CRP) level was $18.6 \mathrm{mg} / \mathrm{l}$. There were no abnormalities of calcium, phosphorus, and uric acid levels in the blood.

Radiographs revealed a widespread radiopaque mass in the middle third of the leg (Fig. 2). The mass was located in the anterior compartment as well as the distal part of the deep posterior compartment of the

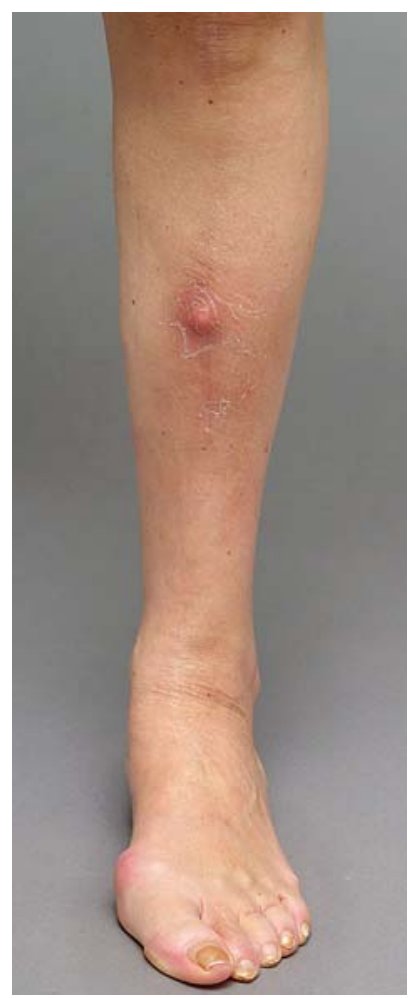

Fig. 1 Anterior view of the left leg showing tender soft tissue mass with erythema on the anterior aspect of the tibia

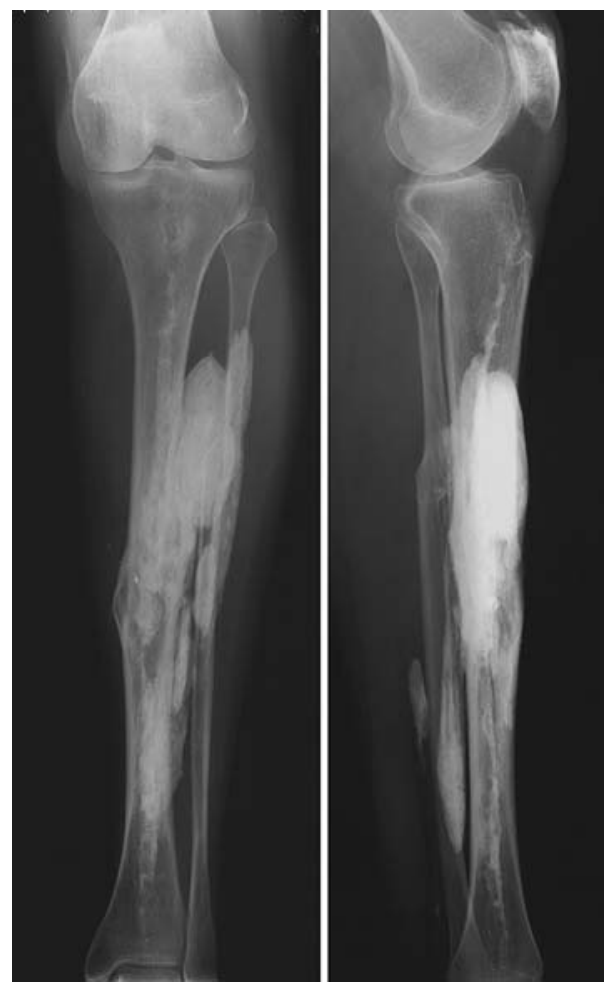

Fig. 2 Preoperative AP and lateral radiograph of the left lower leg showing a large radiopaque mass in the middle third of the leg

extremity. CT showed that the lesion involved the entire tibialis anterior, extensor hallucis longus, and extensor digitorum longus (data not shown). There was fatty degeneration in the posterior compartments with calcification of the distal tibialis posterior muscle. A magnetic resonance imaging (MRI) study revealed a mass with uniformly low signal intensity on both T1and T2-weighted sequences (data not shown). Bone scan did not demonstrate increased uptake by the mass (data not shown).

Angiography demonstrated that the fibularis artery and tibialis posterior artery were patent. The tibialis anterior artery was stenosed in the middle third of the leg (data not shown).

The entire muscular portion of tibialis anterior and extensor digitorum longus was substituted with an inhomogeneous chalk-like induration, which was resected en block. Necrotic parts of the tibia were also removed. There was no evidence of infection. A free functional gracilis transfer was performed with termino-terminal anastomosis with the tibialis anterior artery. The saphena parva vein was used for venous anastomosis. The proximal part of the deep peroneal nerve was used at the level of proximal tibialis anterior muscle branches for the neural connection. The muscle transfer was distally connected to the tendon of tibialis anterior. A tenodesis of extensor hallucis longus and 
extensor digitorum longus was performed. Postoperative splinting of the ankle joint in neutral was done for 6 weeks. Afterwards the patient wore a peroneal splint in order to prevent stretching of the muscle and received electrotherapy. The wounds healed primarily. Intraoperative cultures were negative. Histological investigations revealed dystrophic calcifications of soft tissue with embedded necrotic bone (Figs. 3, 4, 5).

The patient showed no signs of infection in the course of follow-up. The patient's ability to walk improved after surgery. No clinical and radiological signs of recurrence of calcifications were seen at 18month follow-up. The patient was free of pain. Good soft tissue coverage exists (Fig. 6). Active foot extension was observed at last follow-up corresponding to M2 with electromyography-measured muscle activity

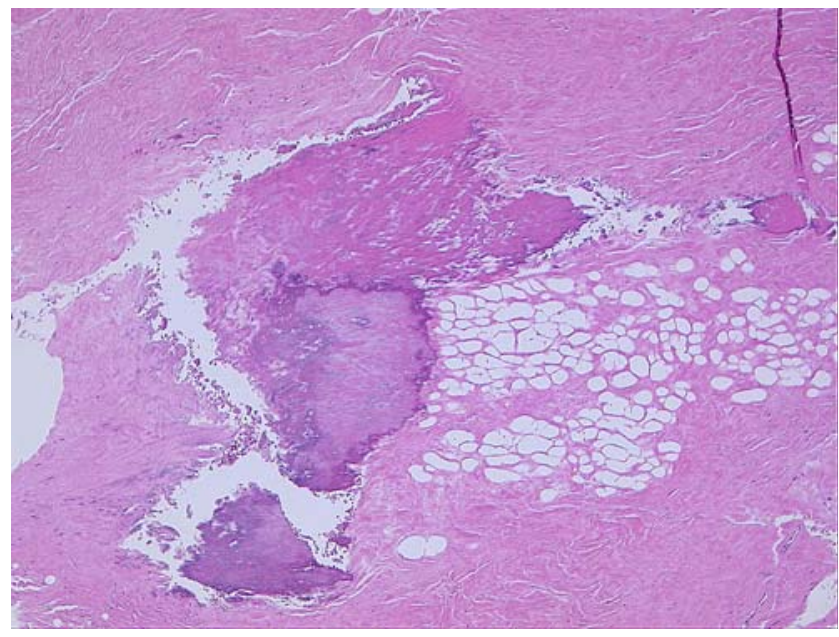

Fig. 3 Highly fibrosed and calcified necrotic soft tissue (hematoxilin and eosin staining; original magnification $\times 25$ )

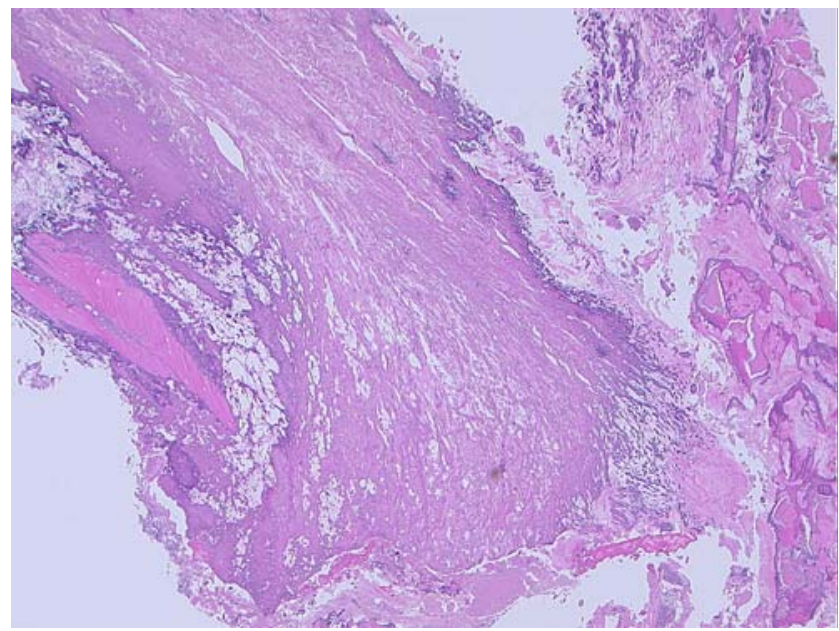

Fig. 4 Necrotic bone embedded in fibrosed soft tissue with dystrophic calcifications (hematoxilin and eosin staining; original magnification $\times 25$ )

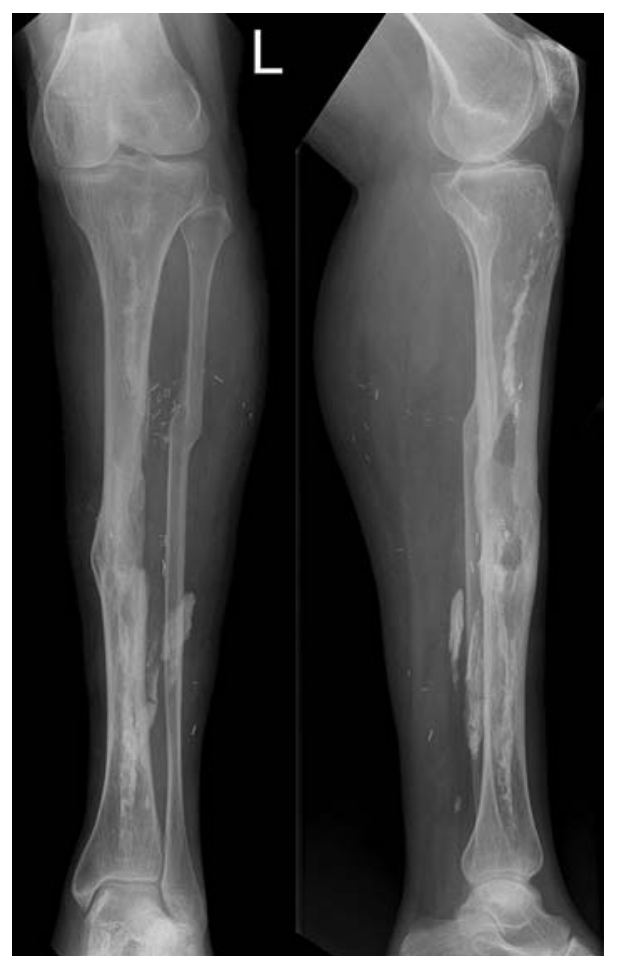

Fig. 5 Postoperative AP and lateral radiograph of the left lower leg showing residual calcifications. No radiological signs of recurrence of calcifications were seen

in the gracilis transfer. Recovery of ankle-joint mobility was limited by contracture of the ankle joint, due to pre-operative existent soft tissue conditions. The active ankle range of motion was between $-10^{\circ}$ of dorsiflexion and $50^{\circ}$ of plantarflexion resulting in mild stepping. The patient could stable walk without any support. She was very satisfied with both functional and aesthetic result.

\section{Discussion}

The etiology and pathophysiological mechanism of this posttraumatic ectopic calcification is difficult to ascertain due to the tremendous delay since injury. These calcifications cannot be explained as ossification of posttraumatic hematoma. Radiologically, the tissue was homogenous and predominantly not located in direct contact with the bone. These calcifications followed muscular fibers and fasciae. Angiography demonstrated a stenosis of the tibialis anterior artery, suggesting the existence of a vascular lesion at the time of injury. The history of initial injury, paralysis, and ischemic myonecrosis, suggested these calcifications followed a compartment syndrome. While contracture and deformities of the lower extremity are well-documented complications of compartment syndrome, dystrophic 


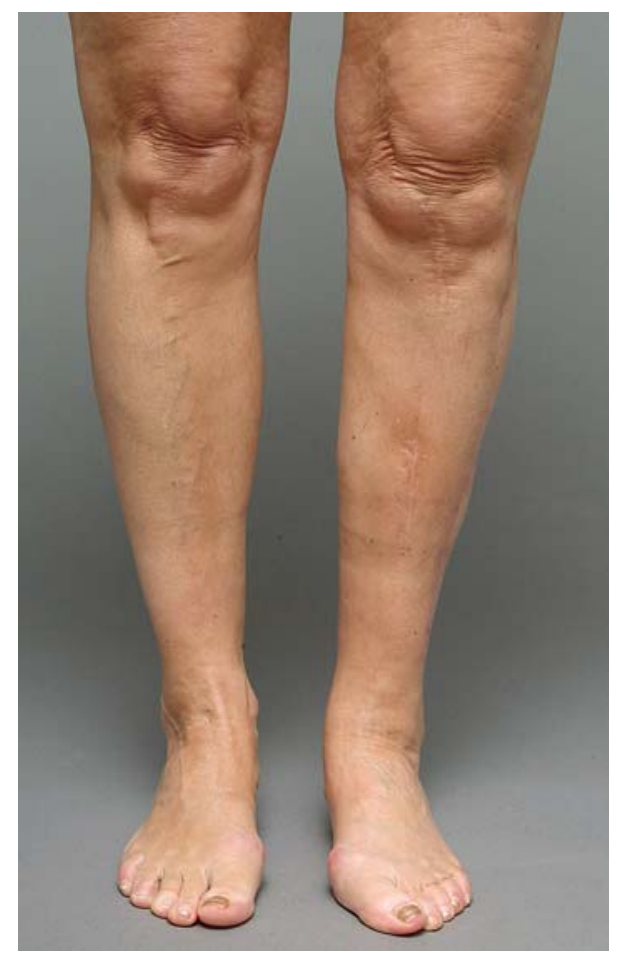

Fig. 6 Anterior view of both legs at 1-year follow-up. After operation, soft-tissue coverage is restored

calcifications are rare occurrences. The pathomechanism of this entity as late sequelae of compartment syndrome is not entirely clear. Certainly, the duration and severity of the initial ischemia, the extent of myonecrosis, and the rate of fibrous tissue regeneration in place of the necrotic tissue may, among other factors, influence its latent presentation. Interestingly the calcifications were mainly situated in the antero-lateral part of the leg, thus essentially affecting the anterior compartment corresponding to the nerve injury. In the early stage of injury ankle movements may cause microtrauma in paretic muscle fibers, thus provoking an increased calcification [6]. This phenomenon has been demonstrated experimentally in rabbits [10]. The loss of normal muscle function could play a role in the development of these changes.

Histological investigation approved characteristic features of dystrophic calcifications (Table 1).

A review of the literature yielded similar cases $[1-5,13]$. Reports on ectopic calcification after compartment syndrome are rare partly because the follow-up period has been too short to detect the calcification, which usually develops years after the syndrome. On the other hand, it is always difficult to prove the existence of a past compartment syndrome in patients with established ectopic calcification because the patients usually are referred after considerable time delay from the initial injury.
While good results after surgery with debridement and tendon transfer have been reported $[1,14]$ an extensive muscle excision appears technically demanding and does not always result in a significant improvement in clinical symptoms [3, 4]. Ninkovic et al. [15] proposed the transposition of the lateral gastrocnemius head to the tendons of the anterior muscle group and the concurrent transposition of its motor nerve to the intact proximal end of the deep peroneal nerve. Successful functional recovery of active dorsiflexion of the foot and toe was achieved with this method. Even though other muscle or tendon transfers like the tibialis posterior tendon transposition over the tibialis anterior can result in functional improvement, but they cannot cover the exposed bone resulting from removed anterior muscular compartment $[16,17]$.

Reinnervated free muscle transfer has proven to be invaluable in numerous reconstructive procedures e.g. soft-tissue tumor, brachial plexus and Volkmann's contracture [17-22]. Several muscles potentially meet the criteria for free functional muscle transfer. Most commonly used muscles include the gracilis, latissimus dorsi, rectus femoris, and the tensor fascia lata muscles. Few reports are available on functioning free muscle transfers in the lower extremity, where injuries have been treated mainly with tendon transfers. Wechselberger et al. [17] used the rectus femoris muscle for restoration of extension of the foot as well as soft-tissue coverage of the lower extremity in three cases with necrosis of all muscles in the anterior compartment after compartment syndrome. Doi et al. [19, 20] reported on two reinnervated free gracilis muscle transfers following radical excision of soft-tissue sarcoma in the extensor muscles of the lower extremity. The transplanted muscles worked as the main activator.

Free functional gracilis muscle transfer is already an established method primarily for restoration of flexor and extensor function in the forearm, elbow flexion, and shoulder flexion [21-23]. Its size, length, and shape most closely approximates that of the muscles, which provide flexion and extension in the hand, flexion at the elbow, as well as, dorsiflexion at the ankle. The latissimus dorsi muscle is an alternative to the gracilis. It has excellent strength and excursion. However, it is bulkier than the gracilis muscle, fans out at its distal insertion, and does not have a distal tendon for weave or repair making it technically more difficult to apply to the lower leg. The fit of the latissimus to the anterior compartment is not satisfactory. The gracilis and latissimus muscles are strap muscles. Their muscle fibers are arranged longitudinal to their direction of contraction. These muscles usually shorten between 40 and $60 \%$ of their stretched length. Thus the range of excursion of the 
Table 1 Differential diagnosis soft-tissue calcifications [11, 12]

\begin{tabular}{|c|c|}
\hline Forms of soft-tissue calcifications & Characteristic features \\
\hline Dystrophic calcifications & $\begin{array}{l}\text { Develop in damaged tissue secondary to minor injury, ischemic necrosis } \\
\text { or necrotizing infectious process in the absence of a generalized metabolic } \\
\text { disorder; usually smaller compared with tumoral calcinosis do not increase } \\
\text { in size; may progress to ossification;associated with venous insufficiency, } \\
\text { parasitic infestation (cysticercosis, dracunculiasis, armillifer armillatus), } \\
\text { Neoplasm [primary bone-forming tumor (osteoma, osteosarcoma), } \\
\text { tumor necrosis], Autoimmune disease (dermatomyositis, scleroderma), } \\
\text { Trauma (heterotopic ossification, compartment syndrome, injection granulomas) } \\
\text { (Prevalence 95-98\%) }\end{array}$ \\
\hline Metastatic calcifications & $\begin{array}{l}\text { Calcium deposits, related to a disturbance in calcium or phosphorus, } \\
\text { fine speckled Calcium, associated with hypervitaminosis D, milk-alkali } \\
\text { (Burnett's)-syndrome, chronic renal failure with secondary } \\
\text { hyperparathyreoidism; often hypercalcemia (Prevalence } 1-2 \% \text { ) }\end{array}$ \\
\hline $\begin{array}{l}\text { Calcium pyrophosphate dihydrate } \\
\text { (CPPD) crystal deposition disease } \\
\text { (chondrocalcinosis) }\end{array}$ & $\begin{array}{l}\text { Wide clinical variety, acute arthritis caused by CPPD crystal-induced inflammation, } \\
\text { most often found in the temporomandibular joint, cervical spine and hand } \\
\text { (tumoral form); knee and wrist (common form), massive deposits of CPPD } \\
\text { crystals which where bordered by fibrous connective tissue (Prevalence } 1-2 \% \text { ) }\end{array}$ \\
\hline Tumoral calcinosis & $\begin{array}{l}\text { Massive calcified deposits in soft-tissue often around major joints; predominant in } \\
\text { adolescents and young adults manifesting before age } 20 \text { years; often familiar, } \\
\text { often occurs in African-Americans; deposits containing hydroxyapatite with lack } \\
\text { of crystalline structures; deposits which where bordered by histiocytes and giant } \\
\text { cells of foreign-body type, hyperphosphataemie, normocalcemia (Prevalence }<1 \% \text { ) }\end{array}$ \\
\hline Fibrodysplasia ossificans progressiva & $\begin{array}{l}\text { Extreme rare, congenital, metabolic disorder of connective tissue characterized } \\
\text { by congenital malformation of the great toe and progressive heterotopic } \\
\text { ossification of tendons, ligaments and fasciae, development in early childhood } \\
\text { and usually results in the premature death of the individual, induced by minor trauma } \\
\text { to the tissue, surgery could exacerbate this condition and should } \\
\text { be avoided (Prevalence }<1 \% \text { ) }\end{array}$ \\
\hline Calcinosis circumscripta & $\begin{array}{l}\text { Affects middle-aged woman and most commonly involves the hand and wrist, } \\
\text { secondary skin infection and fistula formation possible, occurs in scleroderma, } \\
\text { sclerodactyly, systemic lupus erythematosus, high association with } \\
\text { Raynaud's phenomenon }\end{array}$ \\
\hline Calcinosis universalis & $\begin{array}{l}\text { Occur mostly in children, associated frequently with scleroderma or } \\
\text { dermatomyositis, normal serum calcium and phosphorate levels }\end{array}$ \\
\hline
\end{tabular}

gracilis muscle is more than $10-12 \mathrm{~cm}$ in adult muscles [20]. In contrast the rectus femoris and tensor fascia lata muscles are bipennate muscles. Their fibers are oriented at an angle to the direction of muscle contraction. They shorten $40 \%$ of their average fascicule length. Because of their fascicular orientation the bipennate transplants provide increased strength but sacrifice excursion or range of motion $[18,24]$. For restoration of foot extension and large soft-tissue reconstruction Wechselberger et al. [17] preferred the rectus femoris musculocutaneous flap. They considered that the gracilis muscle is not potent enough of generating sufficient force for ankle extension. Otherwise Doi et al. [19] described effective and functional recovery of a functioning gracilis musculocutaneous transfer after radical excision of the anterior compartment in the lower leg.

Daigeler et al. [25] reported on evident but well tolerated donor-site morbidity of the rectus femoris muscle flap due to weakness of knee extension. The true maximal muscular capacity and maximal voluntary contraction values were reduced by 18 and $22 \%$, respectively. There was also a mild voluntary activation deficit. The range of motion in the knee and hip was not influenced by muscle harvesting. Review of the literature showed no significant functional postoperative morbidity in the young and active patient population when the gracilis muscle was elevated [26].

Resection of degenerated muscles along with the ectopic calcification may be beneficial when the necrosis is confined to a localised area in the leg [18], as in our patient. For restoration of function in the anterior compartment we couldnot treat the patient with tibialis posterior tendon transposition because of the resulting soft tissue defect from the resected anterior compartment. Furthermore the deep posterior compartment was partially affected by fatty degeneration. In our case we preferred a free functional gracilis muscle transfer due to moderate soft tissue defect without skin defect.

The follow-up after 18 months showed a very good functional result as well as no relapse of calcification in 
the transfer. Though there was recovery of ankle-joint active dorsiflexion, it was limited due to strength of the gracilis transfer and preexisting contracture of the ankle joint.

Free functional gracilis muscle transfer is a viable reconstructive technique for the treatment of massive ectopic calcification in the leg for this rare pathology. This method can provide active muscle contraction and soft-tissue restoration without significant donor site morbidity.

\section{References}

1. Early JS, Ricketts DS, Hansen ST (1994) Treatment of compartmental liquefaction as a late sequela of a lower limb compartment syndrome. J Orthop Trauma 8:445-448

2. Hyder N, Shaw DL, Bollen SR (1996) Myositis ossificans:calcification of the entire tibialis anterior after ischemic injury (compartment syndrome). J Bone Joint Surg Br 78:318-319

3. Saitoh S, Hata Y, Murakami N, Seki H, Miyauchi S, Takaoka K (2000) Ectopic calcification following tibial fracture: property analysis. Skeletal Radiol 29:609-612

4. Malisano LP, Hunter GA (1992) Case report. Liquefaction and calcification of a chronic compartment syndrome of the lower limb. J Orthop Trauma 6:245-247

5. Viau MR, Pederson HE, Salciccioli GG, Manoli A II (1983) Ectopic calcification as a late sequela of compartment syndrome: reports of two cases. Clin Orthop 176:178-180

6. Osterman K, Lindholm TS (1983) Massive ectopic calcification of the leg following nerve injury. Arch Orthop Trauma Surg 102:82-87

7. Matsen FA III (1973) Compartmental syndrome: a unified concept. Clin Orthop 113:8-14

8. Matsen FA III, Winquist RA, Krugmire RB (1980) Diagnosis and management of compartment syndrome. J Bone Joint Surg Am 62:286-291

9. Mubarak SJ, Owen CA (1977) Doubleincision fasciotomy of the leg for decompression in compartment syndromes. J Bone Joint Surg Am 59:184-187

10. Michelsson JE, Granroth G, Andersson LC (1980) Myositis ossificans following forcible manipulation of the leg. A rabbit model for the study of heterotopic bone formation. J Bone Joint Surg Am 62:811-815
11. Stewart VL, Herling P, Dalinka MK (1983) Calcification in soft tissues. JAMA 250:78-81

12. Resnick D (2002) Diagnosis of bone and joint disorders. 4th edn. WB Saunders, Philadelphia

13. Renwick SE, Naraghi FF, Worrell RV, Spaeth J (1994) Cystic degeneration and calcification of muscle: late sequelae of compartment syndrome. J Orthop Trauma 8:440-444

14. Manoli A II, Smith DG, Hansen ST Jr (1993) Scarred muscle excision for treatment of established ischemic contracture of the lower extremity. Clin Orthop 292:309-314

15. Ninkovic M, Sucur D, Starovic B, Markovic S (1994) A new approach to persistent traumatic peroneal nerve palsy. $\mathrm{Br}$ J Plast Surg 47:185-189

16. Ober FR (1933) Tendon transposition in the lower extremity. N Engl J Med 209:52-55

17. Wechselberger G, Pichler M, Pulzl P, Schoeller T (2004) Free functional rectus femoris muscle transfer for restoration of extension of the foot after lower leg compartment syndrome. Microsurgery 24:437-441

18. Manktelow RT, Zuker RM, McKee NH (1984) Functioning free muscle transplantation. J Hand Surg 9A:32-39

19. Doi K, Ihara K, Kawai S (1998) Limb-sparing surgery in synovial sarcoma of the forearm and lower leg by reinnervated free muscle transfer. Plast Reconstr Surg 102:442-447

20. Doi K, Kuwata N, Kawakami F, Hattori Y, Otsuka K, Ihara K (1999) Limb-sparing surgery with reinnervated free-muscle transfer following radical excision of soft-tissue sarcoma in the extremity. Plast Reconstr Surg 104:1679-1687

21. Barrie KA, Steinmann SP, Shin AY, Spinner RJ, Bishop AT (2004) Gracilis free muscle transfer for restoration of function after complete brachial plexus avulsion. Neurosurg Focus $16: \mathrm{E} 8$

22. Chung DC, Carver N, Wei FC (1996) Results of functioning free muscle transplantation for elbow flexion. J Hand Surg Am 21:1071-1077

23. Hattori Y, Doi K, Abe Y, Ikeda K, Dhawan V (2002) Surgical approach to the vascular pedicle of the gracilis muscle flap. $\mathrm{J}$ Hand Surg Am 27:534-536

24. Gans C, Gaunt AS (1991) Muscle architecture in relation to function. J Biomech 24(1):53-65

25. Daigeler A, Dodic T, Awiszus F, Schneider W, Fansa H (2005) Donor-site morbidity of the pedicled rectus femoris muscle flap. Plast Reconstr Surg 115:786-792

26. Vranckx JJ, Misselyn D, Fabre G, Verhelle N, Heymans O, Van den hof B (2004) The gracilis free muscle flap is more than just a "graceful" flap for lower-leg reconstruction. J Reconstr Microsurg 20:143-148 